\title{
Effect of yttrium 90 on experimental allergic arthritis in rabbits
}

\author{
W. MEIER-RUGE, W. MÜLLER, AND K. PAVELKA \\ From the Institute for Basic Medical Research, Sandoz Ltd., and the \\ Rheumatological University Clinic of Basel, Switzerland
}

\begin{abstract}
Meier-Ruge, W., Müller, W., and Pavelka, K. (1976). Annals of the Rheumatic Diseases, 35, 60-66. Effect of yttrium 90 on experimental allergic arthritis in rabbits. Seventeen rabbits were immunized with complete Freund's adjuvant and bovine serum albumin by the method of Dumonde and Glynn (1962), as modified by Cooke and Jasin (1972). Fifteen weeks after allergic arthritis developed in the knee joint, 8 animals were given an injection of $200 \mu \mathrm{Ci}$ yttrium $90\left({ }^{90} \mathrm{Y}\right)$ into the left joint cavity; 7 were injected with $400 \mu \mathrm{Ci}$. The animals were sacrificed at $2,4,8,12$, and 16 weeks, and at 6 and 12 months after the injection. The right knee joint served as control for assessment of untreated allergic arthritis. Morphological control of the severity of the arthritis was provided by sacrificing 2 uninjected animals 13 weeks after immunization.

After 13 weeks the allergic arthritis progressed to severe inflammation of the knee joint marked by massive round-cell infiltration, oedema, and proliferation of synovial mesothelium in the synovial villi and joint capsule.

Treatment with ${ }^{90} \mathrm{Y}$ was effective 2 weeks after injection with the disappearance of inflammatory oedema and marked regression. of round-cell infiltration. This was accompanied by degeneration of the synovial mesothelium and fibrosis of the subsynovial tissue and synovial vessels as a secondary effect of the radiation.

In the animals with severe allergic arthritis, the healing effects of ${ }^{90} \mathrm{Y}$ were more marked than the secondary effects of the radiation. The secondary effects were dosedependent and consisted of patchy necrosis of the chondrocytes in the fibrocartilage, in the meniscus, in the cruciate ligaments, and in the tangential cartilage of the joint. There was also localized bone-marrow necrosis in the tibia adjacent to the joint.

Treatment with ${ }^{90} \mathrm{Y}$ of arthritic knee joints with the lowest effective dose of the isotope-if necessary with repeated application-seems justified. A single large dose does not have a greater therapeutic effect and causes more radiation damage to the joint.

In view of the possible secondary effects in the joint, the indication for ${ }^{90} \mathrm{Y}$ therapy should be restricted, particularly in young patients, to cases of chronic relapsing arthritis unresponsive to other treatment.
\end{abstract}

Recently the local treatment of arthritis by intraarticular injections of radioactive isotopes has become more common (Prichard, Bridgman, and Bleehen, 1970; Oka and others, 1971; Jalava, 1973; Müller, Fridrich, and Pavelka, 1974a). Because of its optimal radiation properties and low absorption from the joint capsule (Webb, Lowe, and Bluestone, 1969; Gumpel, Williams, and Glass, 1973; Stevenson and others, 1973), the preferred isotope for treating a large joint is yttrium $90\left({ }^{90} \mathrm{Y}\right)$. For smaller joints, other isotopes with low beta-energy are used, such as gold 198, erbium 169, and rhenium 186 (Delbarre and others, 1968, 1973; Müller, Fridrich, and Pavelka, 1974b).

As our earlier studies on the normal rabbit knee joint have shown (Pavelka and others, 1975) ${ }^{90} \mathrm{Y}$ induces fibrosis of the subsynovial connective tissue and synovial villi. The occurrence of these changes, similar to those of joint aging, suggested that treatment of the inflammation with ${ }^{90} \mathbf{Y}$ might cause radiation-induced secondary effects which would exacerbate rather than reverse the pathological joint changes, thereby limiting the effectiveness of isotope treatment in man. We therefore induced adjuvant 


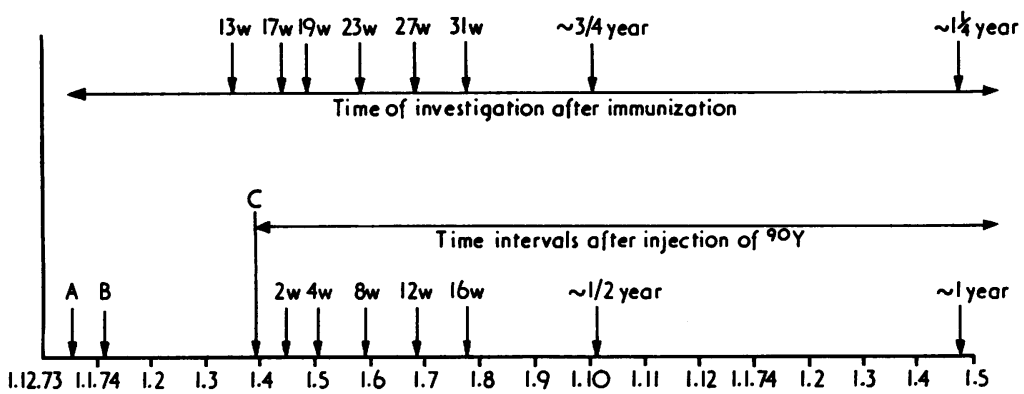

FIG. 1 Experimental course of allergic arthritis in the rabbit with and without ${ }^{90} Y$ treatment. $A=$ Immunization with Freund's adjuvant and albumin; $B=2.5 \mathrm{mg}$ albumin injection into the knee joint; $C=200 \mu \mathrm{Ci}$ or $400 \mu \mathrm{Ci}$ ${ }^{90} Y$ injection into the left knee joint

arthritis in rabbits and compared the morphological changes occurring in untreated animals with those in animals given local injections of ${ }^{90} \mathrm{Y}$.

\section{Methods}

Seventeen male rabbits, weighing $2 \cdot 0-2.5 \mathrm{~kg}$, were immunized by the method of Dumonde and Glynn (1962), as modified by Cooke and Jasin (1972). Under mild anaesthesia (Numal), $1 \mathrm{ml}$ of complete Freund's adjuvant (Difco Ltd., corresponding to $2 \mathrm{mg}$ of lyophilized mycobacteria) and $1 \mathrm{ml}$ of bovine serum albumin (Behring AG, type HD 05, corresponding to $5 \mathrm{mg}$ ) were injected intracutaneously under aseptic conditions into each of 4 shaved skin areas of the back. All the animals tolerated the immunization well.

Three weeks after inoculation, the animals were given an injection into each knee joint cavity of $2.5 \mathrm{mg}$ albumin in $0.5 \mathrm{ml}$ physiological saline. Fifteen weeks later 8 animals were injected with $200 \mu \mathrm{Ci}{ }^{90} \mathrm{Y}$ into the left knee joint cavity and 7 animals were injected with $400 \mu \mathrm{Ci}{ }^{90} \mathrm{Y}$. The right knee joint served as untreated arthritis control in all the animals. Two animals were not injected with ${ }^{90} \mathrm{Y}$ and observations were made of the severity of the arthritis 13 weeks after immunization. The complete plan of the trial is shown in Fig. 1.

\section{HISTOLOGICAL TECHNIQUE}

The knee joint was opened by removing the patella and the joint was fixed for 7 days in Bouin's solution, which was changed twice during the week. After 4 days of fixation the joint was sawn through to give a transverse midsection disc giving a complete picture of the meniscus. The sections were then fixed for the remaining 3 days in Bouin's solution, followed by dehydration of the sections for 4 days in methanol. Without decalcification, they were then embedded in methylmethacrylate by Burkhardt's method $(1966 \mathrm{a}, \mathrm{b})(100 \mathrm{ml}$ destabilized methylmethacrylate, $3.5 \mathrm{~g}$ benzol peroxide, and $25 \mathrm{mg}$ Plastoid $\mathrm{N}$ ). After soaking the sections for 3 days with repeated changing of the methacrylate, the mixture was allowed to polymerize at $37^{\circ} \mathrm{C}$ in vacuo by the methods of Burkhardt (1966a,b), Gardner (1972), and Vitalli (1970).

The polyacrylic resin blocks were cut with a cut-all Zeiss microtome to yield sections $4 \mu \mathrm{m}$ thick which were placed on gelatin-coated slides, covered with cigarette paper, pressed with a small linoleum roller, and dried at about $40^{\circ} \mathrm{C}$.

Before staining, methacrylate was removed from the sections with benzene and they were rehydrated with a series of aqueous ethanol dilutions of decreasing strength.
Staining was carried out as for paraffin sections using the following stains: (1) jaune solide (haematoxylin-acid fuchsin-fast yellow); (2) Giemsa ; (3) toluidine blue (metachromatic staining); (4) azure eosin (Nocht-Maximov).

\section{Results}

Examination of the 2 untreated animals showed that severe arthritis of the knee joint developed 13 weeks after immunization. This was marked by massive round-cell, and to some extent plasma-cell, infiltration of the synovial villi with proliferation of the synovial mesothelium (Fig. 2). The latter also showed

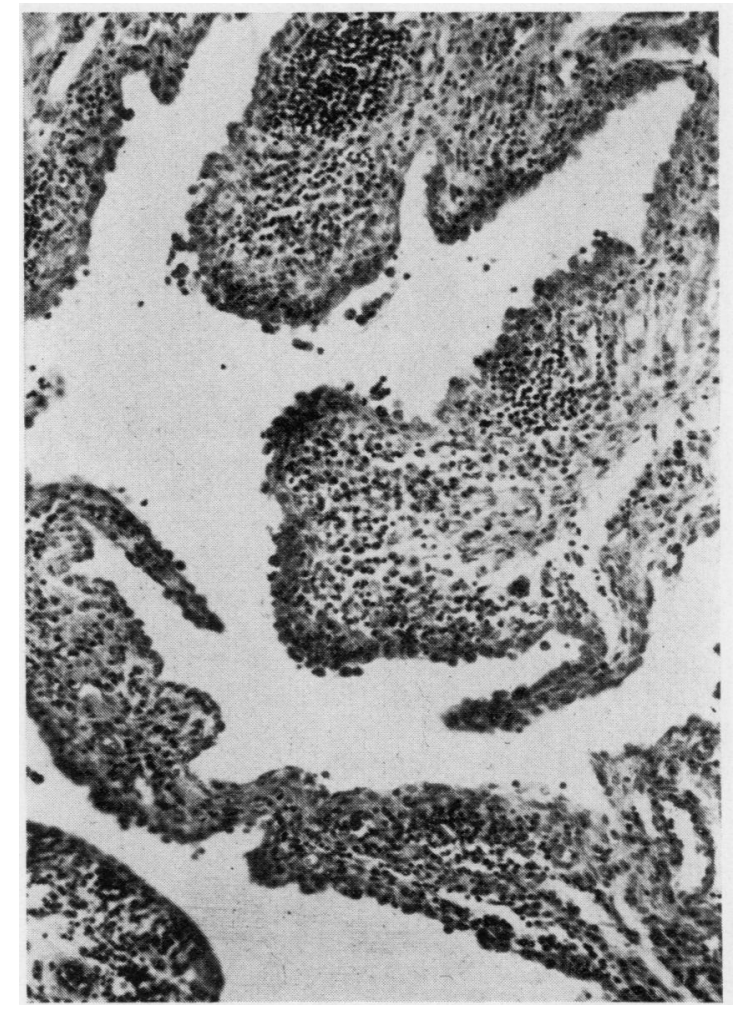

FIG. 2 Allergic arthritis 12 weeks after immunization. Synovial villi of the knee joint showing massive round-cell infiltration and proliferation of synovial mesothelium. Paraffin; haematoxylin and eosin. $\times 120$ 
uneven round-cell infiltration, with oedema of the neighbouring connective tissue. The thin-walled vessels of the subsynovial tissue were hyperaemic and markedly dilated. In the joint cavity there was a moderately protein-rich exudate with a low cell content.

The arthritis was still highly active 17 weeks after immunization. The synovial villi continued to show round-cell infiltration, oedema, and to some extent fibrinoid swellings. Massive proliferation of the synovial mesothelium could be seen in the recess of the joint capsule. A prominent feature was the focal inflammatory synovial changes. In the region of the meniscus the synovial villi showed proliferation of fibrocytes and fibroblasts, a sign of a chronic disease process, and focal proliferation of the synovial mesothelium.

In the animals which 2 weeks previously, i.e. 17 weeks after immunization, had been given injections of 200 or $400 \mu \mathrm{Ci}^{90} \mathrm{Y}$ into the joint cavity, the inflammation had regressed. The round-cell infiltration and oedema in the joint capsule and synovial villi could no longer be seen, and such infiltrations as were

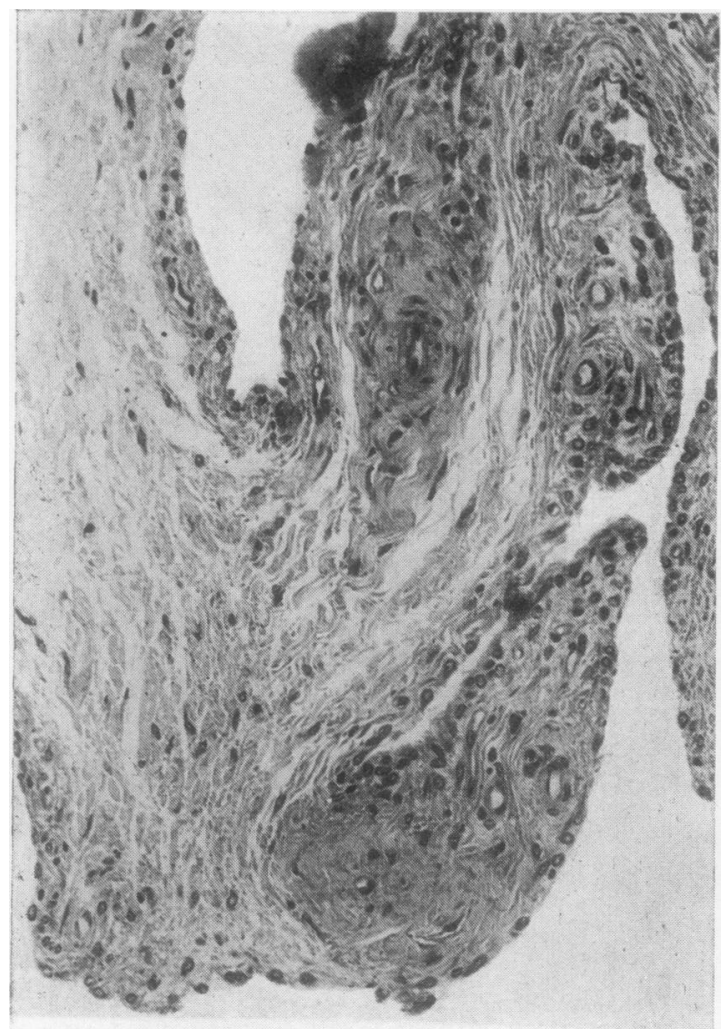

FIG. 3 Femoral parts of the joint capsule in allergic arthritis (31 weeks after immunization) present were small and mostly insignificant. To some extent the synovial cells showed pyknosis or considerable structural breakdown. Signs of synovial regeneration could be seen, particularly in the region of the plicae of the joint capsule, though this was accompanied by severe fibrosis of the subsynovial tissue of the joint capsule (Fig. 3). The vessels showed connective-tissue 'sheathing' or thickening of the walls.

In the treated joints, especially those injected with $400 \mu \mathrm{Ci}{ }^{90} \mathrm{Y}$, pyknosis was observed in the fibrous tissue of the cruciate ligaments and the cartilage of the meniscus together with karyolysis of a few chondrocytes (Fig. 4). A notable additional finding due to the ${ }^{90} \mathrm{Y}$ treatment was a loss of erythropoietic bone marrow in the region of the tibial attachment of the cruciate ligaments.

Nineteen weeks after immunization the treated joints showed the characteristic signs of irradiation injury with fibrosis of the synovial membrane and vessels. The synovial mesothelium was partially regenerated. In the region of the cruciate ligaments there were small defects in the tangential layer of the

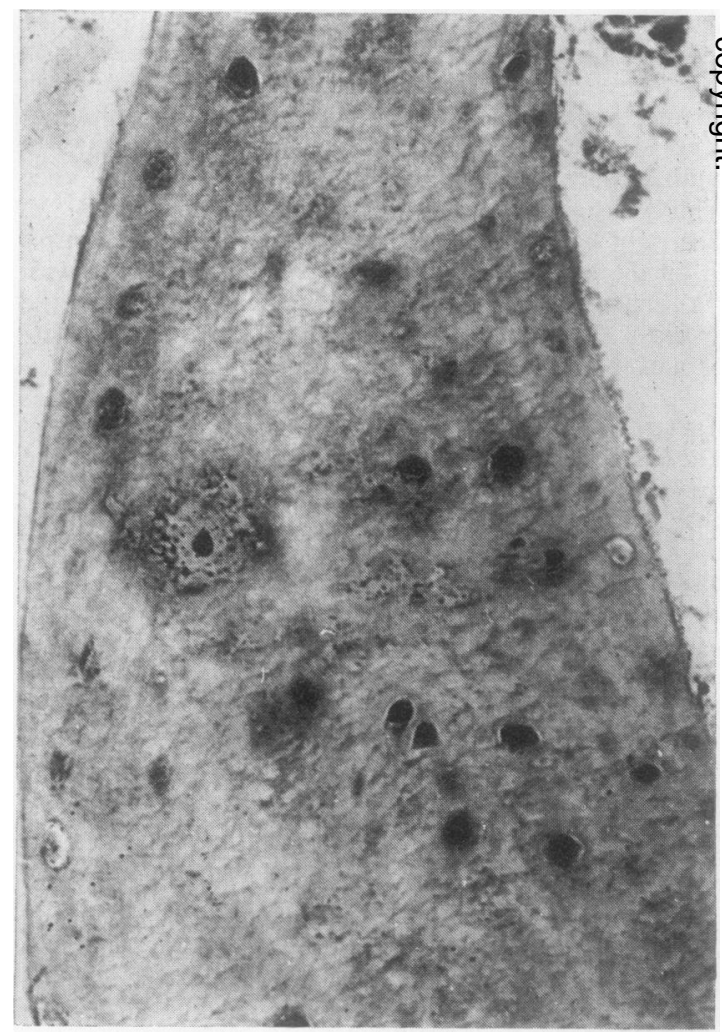

FIG. 4 Meniscus 2 weeks after exposure to $400 \mu \mathrm{Ci}{ }^{90} \mathrm{Y}$. Degeneration of chondrocytes with pyknosis and karyolysis. Polyacrylic resin; toluidine blue. $\times 300$ 
femoral joint cartilage. A few proliferating cartilage cells could be seen in the fibrocartilage. This was a much more prominent finding in the animals treated with $400 \mu \mathrm{Ci}{ }^{90} \mathrm{Y} 8$ weeks before being sacrificed, i.e. 23 weeks after immunization. At this stage there was severe degeneration of cruciate ligament with with localized necrosis. In addition there was incipient regeneration of cartilage cells marked by the appearance of giant cartilage cells and polynuclear chondrocytic giant cells.

Sixteen weeks after ${ }^{90} \mathrm{Y}$ injection of the knee joint, i.e. 31 weeks after immunization, slight signs of arthritis with localized round-cell infiltration in the synovial villi were still to be seen (Fig. 5). The surrounding area of the joint capsule showed fibrous changes. In line with other observations on joints treated with ${ }^{90} \mathrm{Y}$ there were fibrotic changes in the vessels, some of which showed collagenous degeneration and ectasia of the walls.

This relatively normal appearance of the joint contrasted sharply with that of the untreated joint on the other side. There was massive proliferation of the synovial villi in the plicae of the joint capsule, which was enlarged. Both the synovial villi and the subsynovial layers of the joint capsule exhibited diffuse round-cell infiltration (Fig. 6, left) consisting of plasma cell and lymphoid cell elements as well as protein-storing phagocytes. In addition there was proliferation of synovial mesothelium of inflammatory origin. Some of the synovial villi showed deposits of fibrin. Localized fibrinoid degeneration of the tangential cartilage on the tibial side of the knee joint was also observed.

The most serious damage was in the region of the cruciate ligaments (Fig. 6), where fibrinoid necrosis was seen alongside massive round-cell infiltration of synovial villi. Degenerated and polynuclear chondrocytes were present in the fibrous tissue of the cruciate ligaments, together with fibrinoid degeneration and foci of histiocytic and fibroblastic cells (Fig. 6 , right).

These arthritic lesions were still in evidence at 9 and 15 months after immunization, though now mainly confined to the plicae of the capsule, to synovial villi at the base of the meniscus, and less so to the region of the cruciate ligaments. They were marked by considerable collections of phagocytes among the round-cell infiltrations. The plicae of the capsule were enlarged and marked by the presence of synovial villi showing various degrees of inflammatory injury. As in the earlier stages of the arthritis, the border of the synovial mesothelium was seen to be widened.

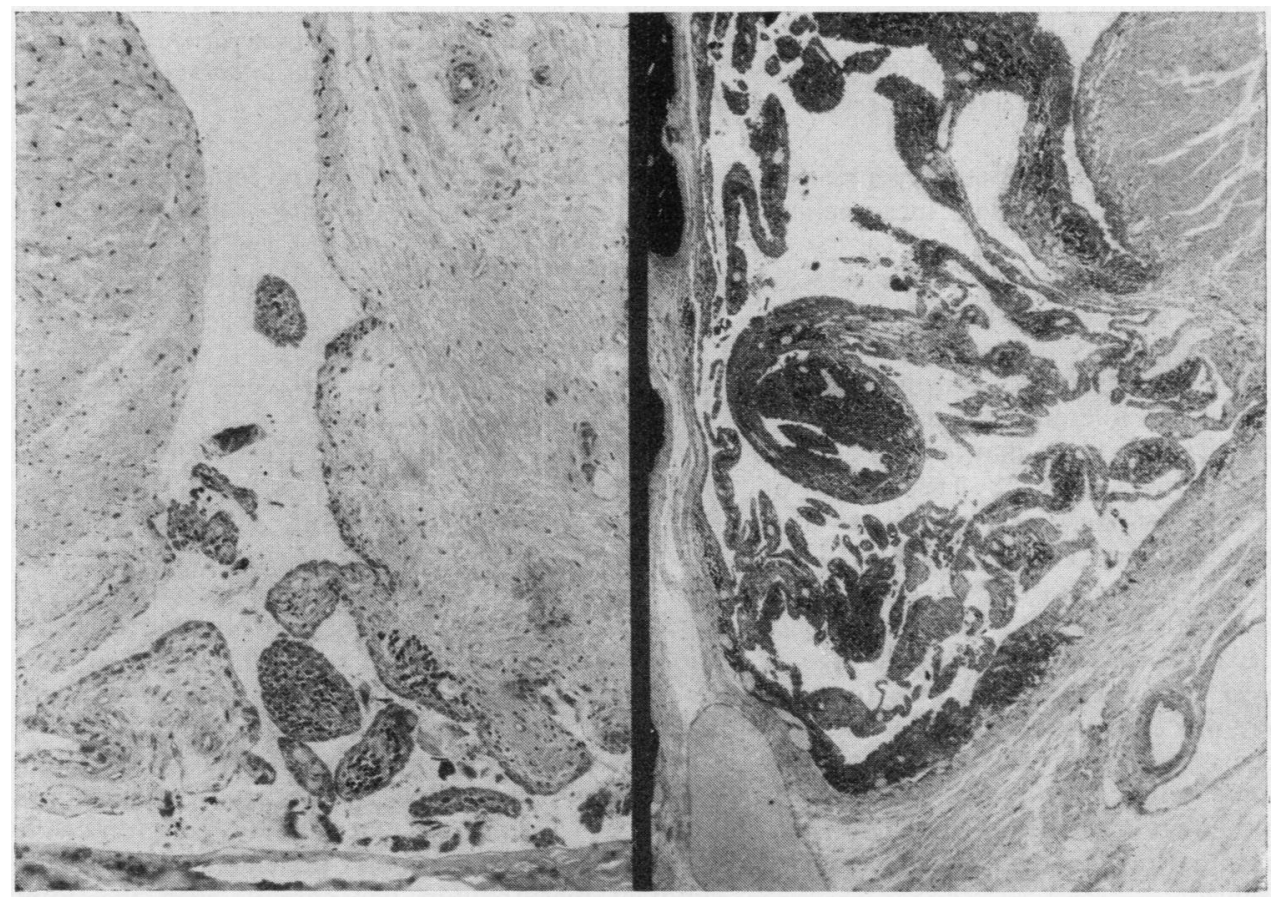

FIG. 5 (Left) 16 weeks after treatment with ${ }^{90} Y$. Slight residual arthritis in the plicae of the joint capsule. Collections of round-cells in synovial villi. Regenerating synovial mesothelium. Polyacrylic resin; toluidine blue. $\times 72$. (Right) Contralateral side with allergic arthritis. Massive proliferation of synovial villi showing round-cell infiltration. Spreading of synovial mesothelium. Polyacrylic resin; toluidine blue. $\times 28$ 


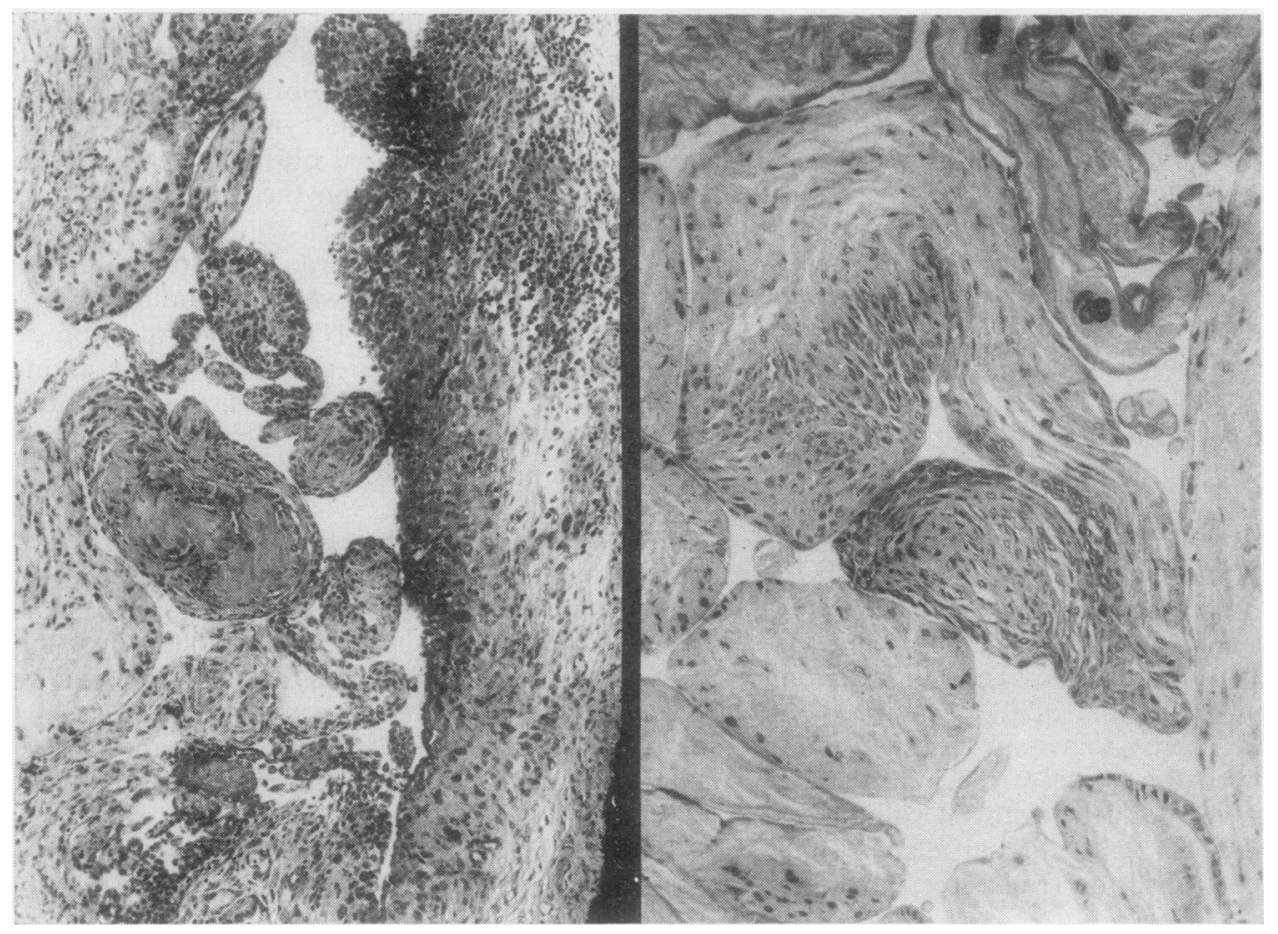

FIG. 6 (Left) Allergic arthritis with fibrinoid necrosis of synovial villi and proliferation of round-cells and synovial meso thelium in the region of the cruciate ligaments of the knee joint 31 weeks after immunization. Polyacrylic resin; toluidine blue. $\times 72$ (Right) Rheumatic granuloma and foci of fibrinoid degeneration in a cruciate liagment in allergic arthritis of the knee 31 weeks after immunization. Polyacrylic resin; toluidine blue. $\times 116$

A few foci of fibrinoid connective-tissue degeneration were present in parts of the synovial mesothelium that had been cut tangentially.

Six and 12 months after injection, the capsules of the treated joints displayed in most cases a normal or only slightly inflammatory degree of infiltration. The synovial villi showed fibrosis of varying severity. In one animal with severe allergic arthritis the inflammation, though still active, had markedly regressed 12 months after treatment with ${ }^{90} \mathrm{Y}$. Destruction of joint cartilage at the periphery and in the region of the cruciate ligaments was considerably less in the treated joints than in the untreated ones (Fig. 7).

As far as the therapeutic effect was concerned, there was no fundamental difference between a dosage of $200 \mu \mathrm{Ci}$ and $400 \mu \mathrm{Ci}{ }^{90} \mathrm{Y}$. In the animals treated with $400 \mu \mathrm{Ci}{ }^{90} \mathrm{Y}$ there was evidence of radiation damage in the tibial bone marrow near the joint as well as lesions in the tangential layer of the peripheral joint cartilage and in the region of the cruciate ligaments. The most serious radiation damage was in the cruciate ligaments themselves.

Attention must finally be drawn to a general observation made on the synovial membrane of the rabbit knee joint. In healthy rabbits 1-2 years old the synovial mesothelium is found principally in the region of the synovial villi in the femoral and tibial plicae of the joint and at the base of the meniscus. In animals with adjuvant arthritis the synovial mesothelium gradually extends over the whole of the joint capsule.

\section{Discussion}

The results show that the local injection of ${ }^{90} \mathrm{Y}$ can be regarded as an effective therapeutic method in allergic arthritis in the rabbit. The inflammatory oedema disappears as early as 2 weeks after injection of ${ }^{90} \mathrm{Y}$. Radiation from the isotope causes fibrosis of the subsynovial connective tissue of the joint capsule and of the synovial villi. It also affects the complex vascular system of the synovial membrane, with closure of some of the vessels occurring.

Signs of degeneration in the synovial mesothelium are seen only during the 2 weeks after ${ }^{90} Y$ injection. Then there is rapid and extensive regeneration of the synovial membrane, though the extent to which the synovial mesothelium has spread over the joint capsule decreases with the increasing age of the rabbit. As noted above, in principle the synovial mesothelium of the nonarthritic rabbit joint is confined mainly to the region of the synovial villi in 


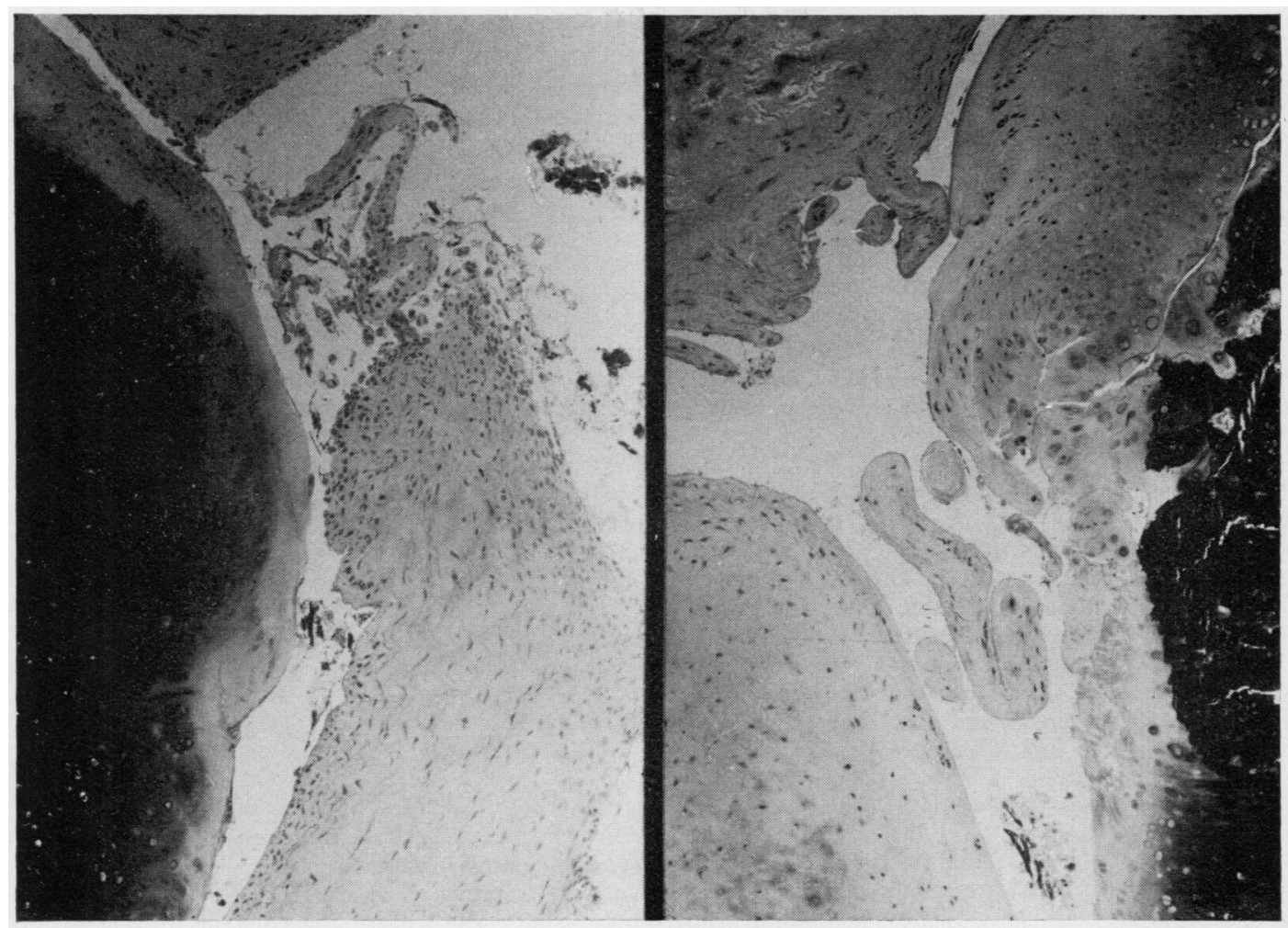

FIG. 7 (Left) Tibial joint cartilage of the knee joint with degeneration of the tangential cartilage 12 months after injection $\frac{\overrightarrow{0}}{3}$ of $400 \mu \mathrm{Ci}{ }^{90}$ Y. Polyacrylic resin; toluidine blue. $\times 72$. (Right) Untreated knee joint on the opposite side. Severe destruction of the tibial joint cartilage due to allergic arthritis 15 months after immunization. Polyacrylic resin; toluidine blue. $\times 72$

the plicae of the knee joint capsule, to the base of the meniscus, and to the synovial villi in the region of the cruciate ligaments. As allergic arthritis develops the synovial mesothelium proliferates, spreads, and gradually extends over the whole of the joint capsule. This proliferation is directly related to the extent of subsynovial round-cell infiltration and of fibrinoid swelling of the connective tissue of the joint capsule.

Small lesions in the tangential layer of the joint cartilage were seen in the joints treated with ${ }^{90} \mathrm{Y}$ particularly when the larger dose of $400 \mu \mathrm{Ci}$ had been injected. This was often conspicuous in the region of the cruciate ligaments and at the periphery of the joint surfaces. In addition, minor radiation damage occurred in the region of the cruciate ligaments with loss of erythropoietic bone marrow in the tibia. It is near these ligaments that the joint cavity is least protected by cartilage and bone (Jalava, 1974).

When the untreated joints are compared with treated joints one year after injection of ${ }^{90} \mathrm{Y}$, the arthritic destruction is seen to be much greater in the untreated joints. However, using a dose of $400 \mu \mathrm{Ci}{ }^{90} \mathrm{Y}$ results in necrosis in the region of the meniscus and cruciate ligaments, with involvement of chondrocytes and reactive chondrocytic giant cells as well as of giant cells in the fibrocartilage of these ligaments. On the other hand, though these changes are important, they are of little significance in comparison with the severe destruction brought about in the region of the cruciate ligaments by allergic arthritis. In less severe arthritis the radiation damage to the cruciate ligaments is the most prominent lesion.

There is no fundamental difference between doses of $200 \mu \mathrm{Ci}$ and $400 \mu \mathrm{Ci}^{90} \mathrm{Y}$. In severe arthritis neither dose supresses the disease process entirely, for some degree of inflammation persists even if slight. Kalliomäki, Jalava, and Möttören (1974) carried out similar studies on rats (Jalava, 1974) using a different experimental design.

The following conclusions can be drawn with regard to the therapeutic effects obtained with the Dumonde-Glynn (1962) experimental model of rabbit allergic arthritis.

(1) Allergic arthritis of the rabbit can be effectively treated with ${ }^{90} \mathrm{Y}$.

(2) In severe arthritis the secondary radiation effects are less severe than the primary effects with this model. 
(3) In order to minimize the secondary effects of radiation the smallest effective dose should be used, if necessary with repeated application (Jalava, 1974).

(4) In view of the appearance of the known secondary effects of therapy with ${ }^{90} \mathrm{Y}$ on the joint cartilage and on the fibrocartilage of the cruciate ligaments, the indications for ${ }^{90} \mathrm{Y}$ therapy should be restricted. ${ }^{90} \mathrm{Y}$ should be reserved for cases of chronic arthritis unresponsive to other treatment and should be restricted in young patients because of the long life expectancy (de la Chapelle and others, 1972; Dolphin, 1973; Stevenson and others, 1973; Ingrand, 1973; Jalava and Salonius, 1974).

\section{References}

BURKhARDT, R. (1966a) Blut, 13, 337 (Präparative Voraussetzungen zur klinischen Histologie des menschlichen Knochenmarkes. 1. Mitteilung)

_- (1966b) Ibid., 14, 30 (Präparative Voraussetzungen zur klinischen Histologie des menschlichen Knochenmarkes. 2. Mitteilung)

Chapelle, A. De la, OKa, M., Rekonen, A., And Ruotsi, A. (1972) Ann. rheum. Dis., 31, 508 (Chromosome damage after intra-articular injections of radioactive yttrium. Effect of immobilization on the biological dose)

CoOKe, D. T., AND JAsIN, H. E. (1972) Arthr. and Rheum., 15, 327 (The pathogenesis of chronic inflammation in experimental antigen-induced arthritis)

Delbarre, F., Cayla, J., Menkes, C., Aignan, M., Roucayrol, J.-C., And Ingrand, J. (1968) Presse méd., 76, 1045 (La synoviorthèse par les radio-isotopes)

-,Menkes, C. J., Aignan, M., Roucayrol, J. C., Ingrand, J., And Sanchez, A. (1973) Nouv. Presse Méd. 2,1372 (Une nouvelle préparation radioactive pour la synoviorthèse: le rhénium 186 colloïdale. Avantages par rapport au calloïde d'or 198)

DolPhin, G. W. (1973) Ann. rheum. Dis., 32, Suppl. 23 (Biological hazards of radiation)

Dumonde, D. C., AND GlynN, L. E. (1962) J. exper. Path., 43, 373 (The production of arthritis in rabbits by an immunological reaction to fibrin)

GARDNER, D. L. (1972) In 'The Pathology of Rheumatoid Arthritis'. Arnold, London

Gumpel, J. M., Williams, E. D., AND Glass, J. I. (1973) Ann. rheum. Dis., 32, 223 (Use of yttrium-90 in persistent synovitis of the knee. I. Retention in the knee and spread in the body after injection)

INGRAND, J. (1973) Ibid., 32, Suppl. 3 (Characteristics of radio-isotopes for intra-articular therapy)

JALAVA, S. (1973) Curr. ther. Res., 15, 593 (Irradiation synovectomy: clinical study of 67 knee effusions intra-articularly irradiated with $90-Y$ resin) (1974) Scand. J. Rheum. Suppl. 4 (Irradiation synovectomy)

-, AND SALONius, A.-L. (1974) Lancet, 1, 807 (Chromosomes of patients treated with yttrium-90)

Kalliomäkı, J. L., Jalava, S., AND Möttönen, M. (1974) Scand. J. Rheum., 3, 25 (On the development of adjuvant arthritis in the joint intra-articularly irradiated by radioactive yttrium ${ }^{90} \mathrm{Y}$ resin)

Müller, W., Fridrich, R., ANd PavelKa, K. (1974a) Dtsch. med. Wschr., 99, 996 (Die Synoviorthese mit Yttrium 90)

-,-1 - (1974b) Therap. Umsch., 31, 483 (Die Radiosynoviorthese)

OKA, M., ReKonen, A., RUOTSI, A., AND SEPPÄLÄ, O. (1971) Acta rheum. scand., 17, 148 (Intraarticular injection of Y-90 resin colloid in the treatment of rheumatoid knee joint effusions)

Pavelka, K., Meier-Ruge, W., Müller, W., And Fridrich, R. (1975) Ann. rheum. Dis., 34, 64 (Histological study of effects of colloidal 90 yttrium on knee joint tissues of rabbits)

Prichard, H. L., Bridgman, J. F., And Bleehen, N. M. (1970) Brit. J. Radiol., 43, 466 (An investigation of radioactive yttrium $\left({ }^{90} \mathrm{Y}\right)$ for the treatment of chronic knee effusions)

Stevenson, A. C., Bedford, J., Dolphin, G. W., Purrott, R. J., Lloyd, D. C., Hill, A. G. S., Hill, H. F. H., Gumpel, J. M., Williams, D., Scott, J. T., Ramsey, N. W., Bruckner, F. E., and Fearn, C. B. D'A. (1973) Ann. rheum. Dis., 32, 112 (Cytogenetic and scanning study of patients receiving intra-articular injections of gold-198 and yttrium-90)

Vitalli, H. P. (1970) In 'Knochenerkrankungen, Histologie and Klinik'. Sandoz, Basel

Webi, F. W. S., Lowe, J., ANd Bluestone, R. (1969) Ann. rheum. Dis., 28, 300 (Uptake of colloidal radioactive yttrium by synovial membrane) 